\title{
Experimentando a fotografia como ferramenta de análise da atividade de trabalho
}

\section{An experience of using photography as an "activity of work" analysis tool}

\begin{abstract}
Resumo
O artigo apresenta uma experiência de Oficina de Fotos, desenvolvida em um hospital público no Brasil. Nesta, a proposta metodológica da Clínica da Atividade lança mão do recurso da fotografia digital, fazendo com que o processo de produção da fotografia se dê também como processo de análise da atividade. No momento seguinte as fotos produzidas são postas em debate, em um diálogo sobre a atividade que se desenvolve em torno dos modos coletivos de fazer e suas controvérsias. Usado no cenário da Vigilância em Saúde do Trabalhador, propicia uma análise em que o conceito de saúde adotado é o de capacidade de renormatizar, desenvolvendo ofícios e coletivos de trabalho.

Palavras-chave: Atividade. Subjetividade. Clínica da atividade.
\end{abstract}

\section{Abstract}

The article presents a Workshop of Photos experience, developed in a public hospital in Brazil. In it, the methodological proposal the Clinic of the Activity uses digital photography, in which the process of production of the photograph is also a process of analysis of the activity. Immediately after produced, the photos are discussed, in a dialog about the activity that is developed around the collective ways of working and their controversies. Used in the Surveillance in Health of the Worker's scenario, it allows an analysis in which the adopted concept of health is the capacity of renormatizing, developing work and collectives of work. Key words: Activity. Subjectivity. Clinic of Activity.
OSORIO, Claudia. Experimentando a Fotografia como Ferramenta de Análise da Atividade de Trabalho. Informática na Educação: teoria \& prática, Porto Alegre, v. 13, n. 1, p. 41-49, jan./jun. 2010.

\section{Claudia Osorio}

Universidade Federal Fluminense

\section{Introdução}

N o período de 1989 a 1995 atuei em uma equipe de Vigilância em Saúde do Trabalhador. Ao ingressar como docente e pesquisadora numa universidade federal afastei-me do trabalho na vigilância. Mas o tema da saúde do trabalhador me acompanhou: durante dez anos mantive uma colaboração com um hospital da rede do SUS, na cidade do Rio de Janeiro, através de sua Comissão de Saúde do Trabalhador. Foram anos fecundos, em que a convivência com os membros dessa comissão e demais profissionais desse hospital, favoreceram a experimentação de caminhos de pesquisa e intervenção em saúde do trabaIhador de saúde. É de uma dessas experimentações que falaremos neste artigo.

Nesta parceria, buscávamos caminhos em que o enfrentamento dos acidentes de trabaIho com perfuro-cortantes e outros problemas de saúde, típicos do ambiente de trabalho hospitalar, fosse feito coletivamente, de modo a produzir, no hospital, uma ampliação dos modos participativos de gestão do trabalho. Deu-se então o encontro entre minhas experiências anteriores, em que usei as ferramentas da Vigilância em Saúde do Trabalhador (MACHADO, 1997) e da Análise Institucional (LOURAU, 1993), com a proposta teórico-metodológica da Clínica da Atividade (OSORIO, MACHADO \& MINAYO-GOMEZ, 2005). 
Na parceria com a Comissão de Saúde do Trabalhador do Hospital e com um grupo de estagiários de psicologia, propus trabalhar estas questões com um dispositivo a que chamamos Oficina de Fotos. Neste artigo, vou lançar mão dessa experiência para debater algumas possibilidades da análise do trabalho, ou da psicologia do trabalho, como dispositivo clínico, ou seja, adequado para produzir um modo de intervenção em saúde (do trabalhador) que tem como objetivo ampliar a vitalidade dos coletivos de trabalho e de seus recursos para a ação.

\section{Atividade e subjetividade}

Na visada teórica aqui proposta, a compreensão da relação entre o trabalho e a subjetividade é centrada na atividade de trabalho como fonte permanente de recriação de novas formas de viver. A subjetividade é entendida como produto da atividade (CLOT, 2006a).

A atividade é sempre mais do que os gestos realizados, passíveis de observação direta. Sujeita a pressões, normas, situações mutantes, "a atividade sempre se realiza em um plano de interferências de intenções, exigindo decisões do operador que deve, então, proteger as suas de outras intenções concorrentes" (MAIA, 2006 , p. 28). Dizendo de outra forma, a atividade é sempre um conflito entre várias atividades possíveis. Sendo a atividade realizada uma ação estabelecida entre outras concorrentes, define-se a atividade de uma forma ampliada. Para além de uma concepção amorfa, desencarnada, da atividade de trabalho, propõe-se incluir neste conceito os conflitos do real. A atividade não é somente aquilo que se faz.

O real da atividade é também o que não se faz, aquilo que não se pode fazer, o que se tenta fazer sem conseguir - os fracassos - aquilo que se desejaria ou poderia fazer, aquilo que não se faz mais, aquilo que se pensa ou sonha poder fazer em outro momento. É necessário acrescentar aqui - um paradoxo freqüente - atividade é aquilo que se faz para não fazer o que tem que ser feito, ou ainda, o que se faz sem desejar fazer. Sem contar o que deve ser refeito. Em matéria de atividade, o realizado não possui o monopólio do real. A fadiga, o desgaste psíquico, se compreende tanto por aquilo que os trabalhadores não podem fazer, quanto por aquilo que eles fazem (CLOT, 2001b, p.50.).
A atividade possui então um volume que transborda a atividade realizada.

Sendo assim,

[...] compreendemos que a atividade exige a mobilização da subjetividade e, portanto, a análise do trabalho, para ser efetiva, precisará dispor de metodologias que levem em consideração a produção de subjetividade, o que, dito de outra forma, faz com que a análise do trabalho tenha que incluir em seus estudos o que se produz naquele que produz enquanto produzindo. (MAIA, 2006, p. 28)

À Clínica da Atividade interessa compreender as relações entre o real e o realizado e em que condições a experiência vivida pode ser, ou vir a ser, um meio de viver outras experiências.

No trabalho se dá a construção coletiva de recursos para ação, constituindo-se o gênero da atividade de trabalho: um conceito que, nessa perspectiva, não remete à divisão sexual do trabalho, mas a um plano coletivo de constituição do trabalho. Para a Clínica da Atividade, o trabalhar é sempre uma dimensão coletiva, mesmo que se desenvolva por um único trabaIhador. Na formulação de Miguel Maia,

Toda atividade de trabalho pode ser entendida como um encontro entre corpos, atravessamentos múltiplos que se agenciam, se interconectam, demandando escolhas e decisões e, portanto, tornando todo trabalho uma atividade de criação. Mais do que um mero executor de tarefas, o trabalhador constitui e é constituído pela sua atividade, sendo ao mesmo tempo produtor e produto, estando presente a capacidade de afetar e de ser afetado. Um trânsito no qual o coletivo devém singular e o singular devém trabalhador e, simultaneamente, o singular devém coletivo e o coletivo devém gênero da atividade, de forma que a competência se produz em uma emergência no e através do plano no qual singular e coletivo não são dicotômicos, mas causas/efeitos [...] de atravessamentos de corpos. (MAIA, 2006, p. 30-31)

Este referencial comum, do qual o gênero é constituído e constituinte, não deve ser entendido como o somatório dos referenciais individuais, como se ele fosse o todo do qual os indivíduos seriam as partes, pois ele possui um componente transpessoal, ou genérico, no sentido de que sendo de todos a ninguém pertence. O gênero se constitui na dimensão 
transpessoal do ofício (CLOT, 2006b) ${ }^{1}$. O gênero é uma espécie de corpo intermediário que permite, por exemplo, que dois trabalhadores que não se conhecem possam ser capazes de se coordenarem eficazmente para realizar um objetivo difícil dentro de um contexto complexo de trabalho, por possuírem um gênero de atividade semelhante, que Ihes facilita a maneira de lidar com as coisas e as pessoas (CLOT, 2001a) em um contexto profissional. Este referencial elaborado em comum estabelece as regras não escritas e não imutáveis em uma situação dialógica que supõe a elaboração comum. Ele inscreve o saber-fazer considerado na história de um coletivo, o coletivo de ofício.

O coletivo de ofício, de acordo com Damien Cru, (apud CLOT, 2006b, p. 128) se define pela existência simultânea de vários trabalhadores, uma obra comum, uma linguagem comum, a existência de regras comuns e o respeito durável de cada um por essas regras, o que supõe "um encaminhamento individual que vai do conhecimento das regras à sua interiorização". Na formulação da Clínica da Atividade, o coletivo de ofício supõe

[...] o exercício de um trabalho sobre o trabaIho, de um 'ofício ao quadrado' coletivamente organizado. [...] deve haver uma história comum de reorganização do trabalho coletivo por um coletivo de trabalho: a história aberta de uma estilização genérica indispensável para conservar uma capacidade de agir em conjunto face ao real. (CLOT, 2006b: p.128)

O conceito de estilo nos leva às renormatizações, às invenções que se faz a partir do gênero profissional e renovando esse mesmo gênero. Na atividade os trabalhadores experimentam variantes dos modos habituais ou já consagrados de agir, ampliando deste modo os recursos coletivos para a ação.

Yves Clot apresenta o gênero da atividade profissional como um instrumento para agir, um respondente profissional

"[...] parte sub-entendida da atividade que os trabalhadores de um dado meio de trabalho conhecem e vêem, atendem e reconhecem, apreciam ou temem; aquilo que lhes é comum e que os reúne sob condições reais de vida; aquilo

1 As traduções de textos originalmente em francês são de responsabilidade da autora. que eles sabem que devem fazer graças a pressupostos avaliativos em comum, sem que seja necessário re-especificar a tarefa a cada vez que ela se apresenta. É como uma 'senha' conhecida somente por aqueles que pertencem ao mesmo horizonte social e profissional." (CLOT, 2006b: p.129)

Singular e coletivo ao mesmo tempo, o gênero é sempre plural, de forma que podemos entender que em toda atividade que se processa concorrem gêneros diferenciados, exigentes de um tempo diferente do prescrito para que possa haver a elaboração comum, só possível se privilegiarmos a formação de coletivos de trabalho. O tempo de produção sem considerar o tempo necessário a esta elaboração comum, tão característico da organização do trabalho contemporâneo, em realidade impede de trabalhar, já que, na acepção da Clínica da Atividade, ter acesso ao gênero e o tempo necessário para dele se apropriar e para expandi-lo é fundamental para o processamento da atividade. Sem esse acesso a uma combinação de regras escritas e não escritas, dificulta-se que o gênero exerça sua função de meio de ação, fazendo com que aqueles que trabalham estejam entregues a si mesmos em uma situação que se degrada (CLOT, 2006a, p. 38), amputados em sua capacidade de agir, em sofrimento psíquico.

No trabalho coletivo, o coletivo de trabalho mobiliza instrumentos genéricos. Quando isso não ocorre, os riscos de desregulação da atividade individual aumentam, com consequências tanto para a segurança do trabalho quanto para a saúde dos trabalhadores. (CLOT, 2006b, p. 128)

Se o debate entre os diferentes possíveis está dificultado ou interrompido, ou seja, se o gênero encontra-se em sofrimento, torna-se então difícil dar sentido a atividade, desenvolver-se pessoal e coletivamente. Quando o gênero não está disponível, em boas condições, decorre daí tanto um prejuízo para a saúde dos trabalhadores quanto para a segurança das operações e instalações.

Estudando detalhadamente aquilo que os trabalhadores fazem, aquilo que eles dizem do que fazem, mas também aquilo que eles fazem do que eles dizem, nós desembocamos em um reconhecimento das possibilidades insuspeitadas pelos próprios trabalhadores (CLOT, 2001a). 
A análise do trabalho apresenta-se então como uma possibilidade de intervenção clínica, que tem como objetivo restabelecer o dinamismo do gênero. Mas isso não significa que nessa perspectiva não se produza conhecimento sobre o trabalho, seus processos de transformação de tarefa em atividade, e outros aspectos importantes. Se trabalho e atividade de trabalho são processos, precisamos pô-los em andamento para sobre eles apreendermos algo.

\section{Metodologia de pesquisa e intervenção}

O que se propõe é uma forma de co-análise do trabalho, praticada no ambiente habitual de trabalho.

É necessário considerar que o analista do trabalho é precedido neste ambiente por aqueles que nele exercem seu ofício. Ele encontra aí sujeitos que já conhecem e interpretam seu meio ambiente de trabalho, tendo atribuído a esse trabalho sentidos que procuram preservar. Há aí uma psicologia prática construída pelos trabalhadores, exercida a fim de decifrar os objetivos e motivações das ações humanas, assim como a reconceber os instrumentos necessários à ação frente aos caprichos do trabalho real. Essa psicologia é uma psicologia do sentido e da eficiência da ação ordinária. É por isso que, comparada com a psicologia científica, ela é tão pessoal, tão coletiva, tão concreta e tão verdadeiramente viva. Encontramos então conceitos cotidianos que organizam a experiência de trabalho, implícitos nas descrições formuladas muitas vezes em um vocabulário metafórico (CLOT, 2006a, p. 125-133).

A análise do trabalho, para levar em conta a experiência dos trabalhadores, deve tomar esses conhecimentos como ponto de partida, colocando-os em diálogo com o saber acadêmico que é trazido pelo analista do trabalho.

Aqueles que têm sua atividade profissional posta em análise não transmitem aos analistas/ pesquisadores verdades sobre seu trabalho. Eles se servem da presença destes analistas para se confrontar com diversos aspectos de seu trabalho, com seus possíveis e impossíveis. A experiência de trabalho pode, na análise que se caracteriza como uma nova experiência, se enriquecer, tomando o gênero de sua atividade profissional como objeto de trabalho, ou seja, como objeto de reflexão coletiva.

$\mathrm{Na}$ aproximação do trabalho como experiência, uma referência indispensável é a distinção entre trabalho prescrito e trabalho realizado. A dimensão vivida do trabalho é sempre uma (re)criação, uma novidade, não pode ser facilmente apreendida em palavras ou descrita previamente, mesmo levando em consideração o depoimento daqueles que trabalham. Numa das referências de nosso trabalho, a ergologia, encontramos os comentários de Yves Schwartz, que diz:

\begin{abstract}
A experiência vivida em situação de trabalho não pode jamais ser adequadamente pré-descrita por palavras combinadas, sequências de frases, uma vez que toda configuração da atividade é em parte inédita. [...] Se o trabalho real difere sempre do prescrito é porque os atores sempre precisam antecipar e fazer a gestão dos acontecimentos, dos eventos aleatórios, variáveis - dos quais fazem parte esses mesmos atores como indivíduos singulares - que fazem com que a ação efetiva não seja jamais aquela prevista conceitualmente; as palavras que a prescrevem [...] formam sintaxes de certa maneira mutiladoras se comparadas aos atos eficazes realmente realizados. (SCHWARTZ, 1993, p. 124)
\end{abstract}

Essa aproximação que Schwartz faz do tema nos remete à questão das metodologias de análise e intervenção. Se a atividade não pode ser pré-descrita, a utilidade que poderá ter uma análise que produza como resultado principal uma descrição será sempre limitada. O trabalho, entendido como enigma, se desvela no seu processo de criação e recriação. Faz-se necessário, então, transformá-lo para compreendê-lo.

Dado que toda tentativa de compreender o trabalho é falha, sendo este sempre um processo em grande parte "invisível" a olho nu, devemos pensar em empregar métodos indiretos para analisar a atividade.

Segundo Vigotski (apud LITIM, 2006, p. 91) "é em movimento que o corpo nos mostra o que ele é" Assim, é somente através de uma experimentação transformadora que a atividade de trabalho pode liberar seus segredos, já que é ao transformar cada realização em recurso para uma nova realização que o real da atividade se manifesta em seus desenvolvimentos. (CLOT apud LITIM, 2006, p. 91) Foi nessa perspectiva que Yves Clot e Daniel Faïta (2000) propuseram a autoconfrontação cruzada como método. 
No método da autoconfrontação cruzada, são feitas filmagens em vídeo de dois trabalhadores que desenvolvem uma mesma atividade, escolhida de forma coletiva, em discussões entre os analistas/pesquisadores e o grupo de referência que acompanha a pesquisa. Em um primeiro momento faz-se uma autoconfrontação simples, em que cada trabalhador comenta as seqüências filmadas em vídeo de sua própria atividade. Este comentário é dirigido ao analista/pesquisador. No segundo momento, configurando a autoconfrontação cruzada, cada trabalhador produz um novo comentário, das mesmas seqüências filmadas, agora dirigido não apenas ao analista/pesquisador, mas também ao colega (o outro trabalhador filmado). Os comentários dirigidos ao analista do trabalho e ao par, colega da mesma profissão, não serão os mesmos.

Neste processo há uma atividade de análise, feita sobre a atividade filmada. Esta análise é voltada para seu objeto - os registros em vídeo - mas também para o analista/pesquisador e para o colega. Ele procura, em cada um desses dois interlocutores, pistas de como agir sobre eles. Como falar de seu trabalho ao analista/pesquisador? E como fazê-lo ao dirigir-se ao colega? Ele não procura de imediato em si, nos seus próprios conhecimentos, mas nos outros. Deste modo, ele verá sua própria atividade pelos olhos de outros. E irá encontrar algo novo, sem que tenha necessariamente procurado (CLOT, 2004).

Em nossa experiência propusemos usar não filmagens em vídeo, mas registrar a atividade em fotos. As fotos trazem as marcas da atividade que será objeto de análise.

Inicialmente escolhemos a fotografia como meio de registro por questões de viabilidade técnica. Em primeiro lugar, a filmagem em vídeo exige da equipe de pesquisa recursos de filmagem e de edição de que não dispúnhamos. Em segundo lugar, a realização da análise na autoconfrontação cruzada se dá em um espaço de tempo ${ }^{2}$ não compatível com a formação de alunos de psicologia e residentes de saúde pública, um dos objetivos de nossa colaboração com o Hospital. Necessitávamos de um método mais leve.

2 De acordo com o que é apresentado em reuniões de pesquisa da Equipe de Clínica da Atividade (CNAM-Paris), as intervenções que utilizam o método da autoconfrontação cruzada duram, na maioria dos casos, cerca de dezoito meses.
Mais leve, mas não mais simples, pois fazer as fotos é uma atividade sobre sua atividade cotidiana, é produzir novas realidades (MAURENTE \& TITONNI, 2007).

Observamos então que seria possível levar os próprios trabalhadores a fazerem as fotos a serem analisadas: a máquina fotográfica poderia produzir um efeito interessante, de distanciamento e de produção de espaço para o diálogo interior, ou seja, para um diálogo consigo e com o gênero profissional em questão.

Essas mesmas marcas - fotos - são então discutidas com pares e analistas/pesquisadores, devendo o fotógrafo dizer porque as fez da forma como fez.

\section{Diálogos entre pares, sobre e com o trabalho}

A primeira Oficina de Fotos que realizamos se deu, em 2005, numa manhã, das 8 às 12 horas, e foi seguida de uma reunião de restituição, de uma hora de duração, realizada após 4 semanas.

Para trazer o profissional de saúde para o lugar de co-analista, propusemos que os trabalhadores de saúde participantes da Oficina produzissem, eles mesmos, o material a ser analisado: fotos de situações positivas e fotos de situações negativas para a saúde do profissional de saúde.

Nas Oficinas são usadas máquinas fotográficas digitais, de modo a propiciar a análise imediata do material, sem necessidade de impressão. Em um grupo de 12 profissionais participantes foram organizados 4 sub-grupos, cada um portando uma máquina e acompanhado de um monitor encarregado de dar suporte à tarefa, sem interferir na escolha dos temas. Antes de se dirigir a seus setores de trabalho o sub-grupo discutiu o que iria fotografar. Dirigiu-se ao local escolhido tendo um tempo definido para o retorno.

Para definir para onde dirigir a objetiva, fazse necessário um primeiro debate entre pares. São três pessoas, com uma única máquina fotográfica, que têm como tarefa fotografar situações em que poderão aparecer objetos, mas também outros trabalhadores do hospital, pacientes ou familiares de pacientes.

Neste momento, como nos próximos, se dão diálogos reais e virtuais. Estes, os virtuais, talvez venham a se tornar audíveis na discussão 
em que entrarão outros interlocutores, que não compartilham do mesmo gênero de atividade profissional: os componentes da Comissão de Saúde do Trabalhador e os coordenadores da Oficina - no caso, pesquisadores / psicólogos e alunos ligados ao curso de psicologia.

Cada sub-grupo tinha a tarefa de mostrar ao grupo maior 5 fotos de situações positivas e 5 de situações negativas. Os sub-grupos retornaram com muitas fotos e fizeram então uma seleção. As fotos selecionadas pelos 4 sub-grupos foram exibidas com o auxílio de data-show e discutidas uma a uma. Ao final foram selecionadas, dentre as 40 fotos discutidas, 10 fotos para compor um pôster a ser apresentado na Assembléia Científica anual do Hospital. Neste pôster, os participantes da Oficina figuraram como fotógrafos. A partir de então outras Oficinas de Fotos foram realizadas com pequenas variações na sua dinâmica, buscando sempre desenvolver a proposta metodológica da Clínica da Atividade.

A intervenção aqui proposta busca mais do que conhecer, analisar ou denunciar as formas de dominação e sofrimento existentes: busca provocar as possibilidades que os trabalhadores têm de criar e recriar recursos para sua atividade profissional. 0 dispositivo instalado deve levar o trabalhador à posição de observador de seu próprio trabalho. $\mathrm{O}$ analista do trabalho, como interlocutor, busca possibilitar que o trabalhador se surpreenda com aquilo que, por muito familiar, já passava desapercebido. E favorecer que os diferentes modos possíveis de enfrentamento do real da atividade sejam postos em debate, desenvolvendo o gênero e ampliando suas possibilidades como instrumento para a ação de cada um.

$\mathrm{Na}$ Oficina de Fotos as várias etapas da tarefa proposta exigem dos participantes por o trabalho de todo dia em debate. Modos diferentes de fazer e pensar o trabalho vêm a baila quando se tem como tarefa coletiva definir o que fotografar, o que não fotografar, como fotografar as situações escolhidas, o que e como apresentar para o debate com um grupo maior. Este debate se dá inicialmente num grupo restrito de pares, na presença de um monitor. Amplia-se, a princípio, com interlocutores virtuais: deve-se definir o que será apresentado ao grupo maior e ao analista do trabalho que coordena a Oficina. Prossegue com a definição do que e como apresentar ao Hospital, através de um pôster para a Semana Científica: o que se deseja por em debate com as hierarquias, com um público amplo de pares e visitantes, como amostra da atividade realizada, suas características e dificuldades? Com esse instrumento, o ofício fala, diálogos diversos são entabulados em diferentes planos que se cruzam.

No exemplo que trago pudemos observar algumas características do trabalho que faz sentido para as enfermeiras, técnicas e auxiliares de enfermagem do hospital.

Em varias fotos aparece o trabalho realizado em meio a relações de colaboração, principalmente interprofissional: por exemplo, o momento em que uma médica e uma enfermeira trabalham juntas em uma bancada (Foto 1$)^{3}$.

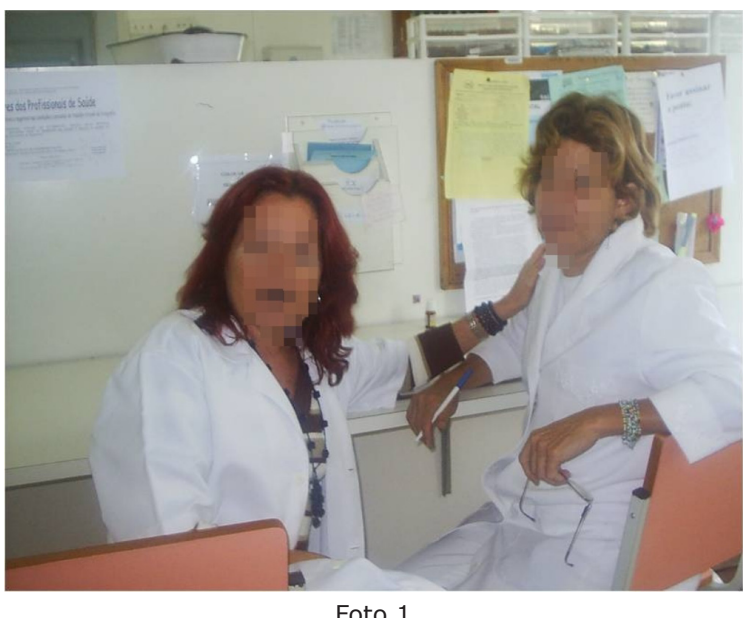

A boa organização, ou a ordem, é tida como facilitadora do trabalho bem feito, sendo algo que favorece a saúde do trabalhador de saúde. Esse é o caso de um almoxarifado do centro cirúrgico, bem equipado e com os materiais perfeitamente organizados (Foto 2). Já a desorganização é apontada como algo que agride a saúde do trabalhador de saúde. Assim muitas situações que são relacionadas à maior qualidade da atenção prestada ao doente são apontadas como positivas para a saúde do trabalhador da assistência.

3 As fotos foram tiradas com o conhecimento e permissão de todos os profissionais e usuários presentes, que permitiram também seu uso em trabalhos acadêmicos. Quando necessário, os rostos foram editados para impedir a identificação. 


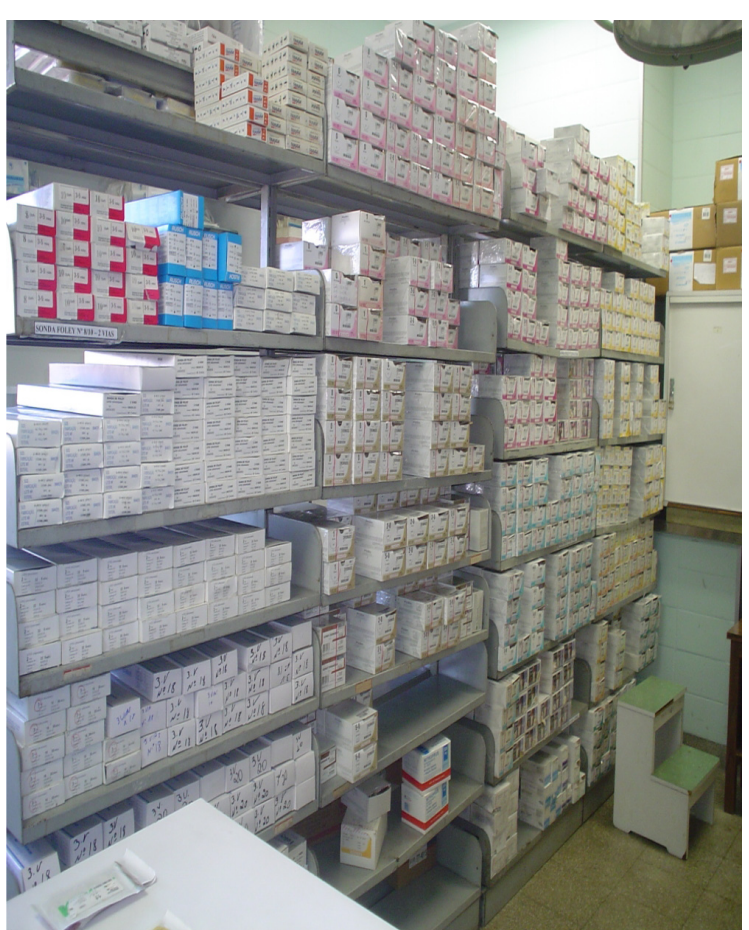

Foto 2

Surgem também como positivos a possibilidade de momentos de pausa e descanso (Foto 3), a capela como local de recolhimento, as flores (Foto 4) e a linda vista que se tem de algumas janelas do hospital.

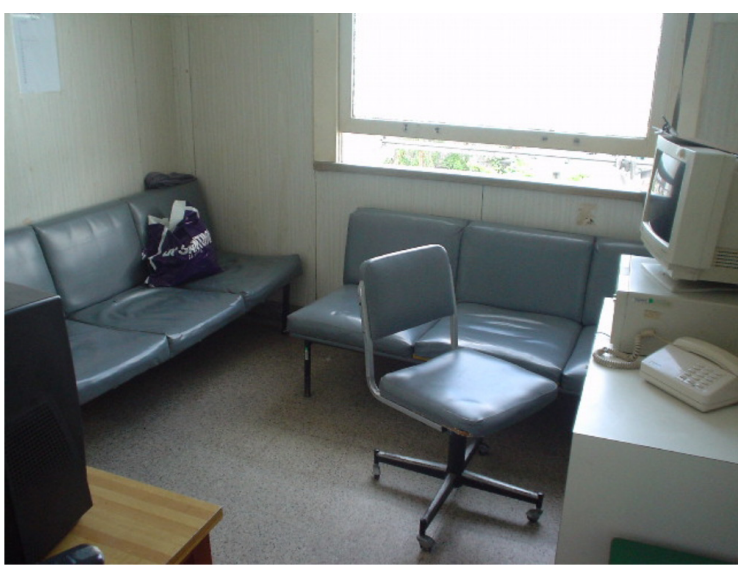

Foto 3

As fotos e suas análises trazem ao debate a complexidade do trabalho. A mesma foto do espaço interno do hospital, com lindas flores (Foto 4) apresenta ao fundo as rampas construídas para um possível escape de emergência. Mas não estão bem conservadas, lembram os participantes, e estão escorregadias.

As polêmicas comparecem também no que diz respeito ao trabalho em equipe (Foto 1 ). Se todos concordam que essa colaboração é positiva, os modos de ver as relações de hie-

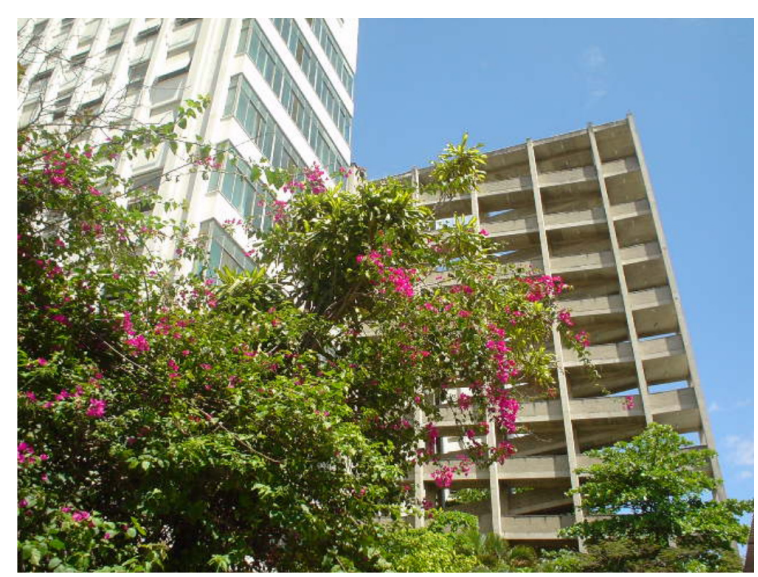

Foto 4

rarquia não são consensuais: algumas enfermeiras participantes consideram a hierarquia importante, necessária, enquanto outras defendem a construção de relações mais horizontais.

A controvérsia também está presente na discussão da presença de acompanhantes, em geral familiares, junto ao doente internado (Foto 5). A foto foi tirada por enfermeiras que consideram essa presença positiva, mas muitos participantes trouxeram as dificuldades existentes no manejo da situação.

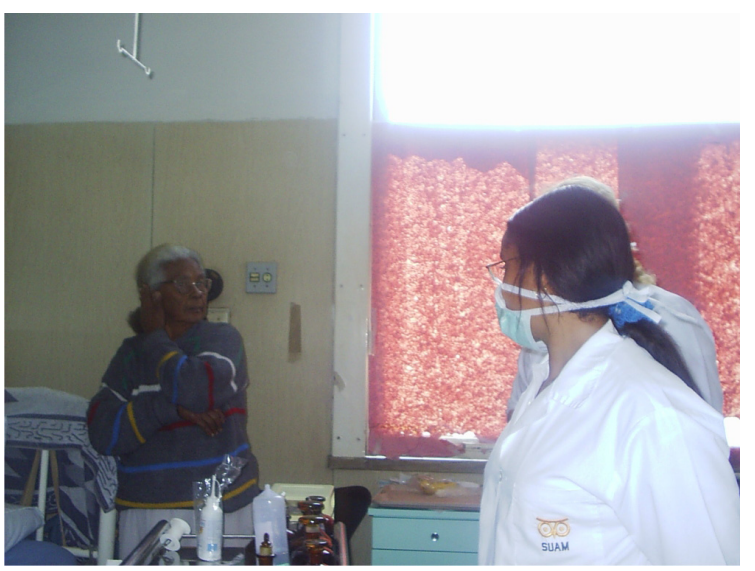

Foto 5

Após o evento científico em que o pôster foi exibido, foi feita uma reunião de restituição. Nesta foram relatados outros diálogos sobre o trabalho que teriam sido disparados pela Oficina ou pela exibição do pôster. Foi relatado também que, ao saber que alguns setores de trabalho dispunham de salas de descanso, outras equipes que não dispõem destes espaços em seus setores de trabalho estavam se mobilizando para produzir para si mesmas algo similar. 
Retomando os aspectos teórico-metodológicos, na Oficina de Fotos:

- Usando a máquina fotográfica como instrumento, desloca-se o trabalhador para o lugar de observador e analista do seu trabalho. Também o analista/pesquisador do trabalho é instrumento do debate sobre o trabalho que se instala, já que um novo interlocutor também induz o mesmo deslocamento.

- Faz-se o debate sobre uma marca do trabalho: uma marca produzida coletivamente, já como fruto do diálogo que põe o gênero em manutenção; deste modo, o debate se faz sobre a atividade, evitando a personalização e o julgamento sobre as escolhas individuais. As polêmicas suscitadas são trazidas sem que se considere que há necessariamente uma verdade, ou que o consenso seja o objetivo. Ao contrário, a controvérsia foi aceita como um recurso para ampliação de recursos coletivos para a ação.

- Por último, mas não menos importante, o debate se faz de modo recorrente, favorecendo deslocamentos, elaborações e re-elaborações, nas análises que se produzem.

\section{Considerações finais}

No momento atual observamos, na maior parte dos locais de trabalho, gêneros que não contém os recursos de que os trabalhadores necessitam para o enfrentamento dos dilemas da atividade. Aumentam as exigências e reduzem-se os recursos existentes para fazer frente a essas exigências. Nesta situação, os coletivos de trabalho enfraquecidos encontram dificuldades em fazer a necessária manutenção dos recursos para a ação que compõem os gêneros de atividade profissional a que nos referimos acima. A atividade clínica em Psicologia do Trabalho é demandada de diversas formas. Esse é então o gênero de atividade profissional que cabe a nós desenvolver.

$\mathrm{E}$, retomando o que foi apresentado inicialmente, o desenvolvimento no Brasil de uma rede de vigilância em saúde do trabalhador, coloca para os profissionais de saúde de diferentes inserções uma convocação à qual devemos responder. E responder contribuindo para um gênero "Saúde do Trabalhador" em que se destaquem seus eixos mais libertários e não aqueles mais ligados a propostas de controle e disciplinamento.

\section{Referências}

CLOT, Yves. A função psicológica do trabalho. Petrópolis: Editora Vozes, 2006 a.

CLOT, Yves. L'activité entre l'individuel et le collectif: approche développementale. In : VALLERY, G. \& AMALBERTI, R. (dir.). L'analyse du travail en perspective : influences et évolutions. Octarès : Toulouse, 2006b. P. 127-139.

CLOT, Yves. Clinique du travail et clinique de I'activité. In : CLOT, Y. \& LHUILIER, D. (dir.). Nouvelle Revue de Psychosociologie, v. 1, p. 31-44, 2006c.

CLOT, Yves. Le travail entre fonctionnement et développement. Bulletin de Psychologie, v. 57, n. 1, p. 5-12, 2004.

CLOT, Yves. Éditorial, Éducation Permanente : Clinique de l'activité et pouvoir d'agir, v. 146, p. 7-16, 2001 a.

CLOT, Yves. Clinique du travail, clinique du réel. Le Journal des Psychologues, n. 185, $2001 \mathrm{~b}$.

CLOT, Yves. Le travail sans I'homme ? Paris : Éditions La Découverte, 1995.

CLOT, Yves \& FAÏTA, Daniel. Genres et styles en analyse du travail : Concepts et méthodes, Travailler, 4, p. $7-42,2000$.

CRU, Damien. Les règles du métier. In Plaisir et souffrance dans le travail v. 2. Paris: AOCIP, 1957-1988. 
LITIM. Malika. Les histoires du travail: un instrument du développement du métier et de l'activité professionnelle. Une analyse de l'activité soignante en gérontologie. 2006. Tese (doutorado). CNAM, Paris, 2006.

LOURAU, René. Análise institucional e práticas de pesquisa. Rio de Janeiro: Editora UERJ, 1993.

MACHADO, Jorge. Processo de Vigilância em Saúde do Trabalhador. Cadernos de Saúde Pública v.13, suplemento 2, p. 33-45. 1997.

MAIA, M. A. B. O corpo invisível do trabalho: cartografia dos processos de trabalho em saúde. 2006. Dissertação (Mestrado) Programa de pós Graduação em Psicologia - Universidade Federal Fluminense, Niterói, 2006, BR-RJ.

MAURENTE, Vanessa \& TITONNI, Jaqueline. Imagens como estratégia metodológica em pesquisa: a fotocomposição e outros caminhos possíveis. Psicologia e Sociedade, v. 19 n. 3 p. 33-38, 2007

MINAYO-GOMEZ, Carlos \& THEDIM-COSTA, Sonia. A construção do campo da saúde do trabalhador: percurso e dilemas. Cadernos de Saúde Pública, v.13, suplemento 2, p. 21-32, 1997.

ODDONE, Ivar, RE, Alessandra \& BRIANTE, Gianni. Redécouvrir l'expérience ouvrière: vers une autre psychologie du travail? Paris : Messidor, 1981.

OSORIO, Claudia, MACHADO, Jorge \& MINAYO-GOMEZ, Carlos. Proposição de um método de análise de análise coletiva dos acidentes de trabalho no hospital. Cadernos de Saúde Pública, v. 21, n. 2, p. 517-524, 2005.

OSORIO DA SILVA, Claudia. \& OLIVEIRA, Noeli. Intervenções em Saúde do Trabalhador: Psicólogos numa Comissão de Saúde do Trabalhador num Hospital Geral Público no Rio de Janeiro. Revista do Departamento de Psicologia - UFF, v.11, n. 1, p. 40-50, 1999.

PROT, Bernard. La fonction du clinicien dans les méthodes de clinique de l'activité. In : CLOT, Y \& LHUILIER, D. (dir.). Nouvelle Revue de Psychosociologie v.1, p. 31-44, 2006.

SCHWARTZ, Y., 1993; "C'est compliqué". Activité symbolique et activité industrieuse. Education Permanente v. 116, p. $119-131,1993$.

Recebido em maio de 2010.

Aprovado para publicação em junho de 2010

\section{Claudia Osorio}

Professora adjunta no Departamento de Psicologia da Universidade Federal Fluminense; Atua na Pós Graduação em Psicologia - Estudos da Subjetividade; Doutora em Saúde Pública - Rio de Janeiro-RJ/Brasil.

Email: claudiaosorio@terra.com.br 